ID13292

\title{
PERSONALITY AND JOB PERFORMANCE: USING INNOVATIVE TECHNIQUES TO IMPROVE PREDICTIVE VALIDITIES
}

\begin{abstract}
Personality is important to job performance. Yet while meta-analyses have repeatedly shown that self-rated personality traits can significantly predict overall job performance, the actual amount of variance explained is low. Improvements in predictive validities have been found by employing innovative techniques such as utilizing: narrow measures (facets) or observer-ratings of personality; situational specificity; or narrow measures of job performance. Furthermore, most practitioners are interested in specific traits that are predictive of specific jobs, yet very little scholarly research has explored outcomes based on the narrow job requirements regularly utilized by practitioners.

We combined these suggestions and explored observer-ratings of narrow personality facets predicting narrow measures of job performance. This large-scale study started by developing an inventory for work-personality facets. Findings suggest that at least 51 personality facets can describe work-personality. We then examined the correlations of 51 facets based on observer-ratings, with 9 job performance outcomes. Integrity, leadership, selfdiscipline and empathy showed the highest correlations across multiple outcomes. Lastly, we selected a few facets as predictors of each outcome, and found that combining two or three facets can explain up to $30 \%$ of the variance in narrow job performance measures. Implications for theory and future research directions are discussed.
\end{abstract}

\section{Keywords:}

Selection - Non-cognitive predictors; Facets of Performance; Employee Characteristics 
ID13292

\section{PERSONALITY AND JOB PERFORMANCE: USING INNOVATIVE TECHNIQUES TO IMPROVE PREDICTIVE VALIDITIES}

Personality is important to job performance; meta-analyses published over the years have repeatedly shown that self-rated personality traits can significantly predict overall job performance (Barrick \& Mount, 1991; Barrick, Mount, \& Judge, 2001). Yet these same metaanalyses showed only weak to moderate validities, with variance explained ranging from $0.1 \%$ to $5.8 \%$. There is widespread bemusement that personality does not predict job performance better than it does; further empirical work has suggested that validities may be increased by utilizing innovative techniques. For instance, measuring personality at the narrow facet- rather than the broad factor-level (Dudley, Orvis, Lebiecki, \& Cortina, 2006; Judge, Rodell, Klinger, Simon, \& Crawford, 2013; Woo, Chernyshenko, Stark, \& Conz, 2014); using observer-ratings rather than self-ratings (Connelly \& Ones, 2010; Oh, Wang, \& Mount, 2011); considering the work-place context (Heller, Ferris, Brown, \& Watson, 2009); measuring job performance as narrow criterion (Bartram, 2005); or combining narrow measures on both sides of the predictor-outcome equation (Bartram, Warr, \& Brown, 2010; Tett, Steele, \& Beauregard, 2003). Moreover, there are personality traits that are "beyond the Big Five" (Paunonen \& Jackson, 2000; Saucier \& Goldberg, 1998); these traits that are missing from most personality studies are likely to be of value in explaining workplace behaviors (Hough, 1992). This large-scale study is the first to combine all these innovative techniques in an effort to improve the validities of personality when predicting job performance.

\section{Facets beyond the Big Five}

Perhaps the low predictive validities are due to an overreliance on investigating personality at the factor level. Factors are not personality traits per se, but rather groupings of 
ID13292

similar traits (Costa \& McCrae, 1992a). The term facet designates the lower-level, narrower traits, that are located within each of the higher level, broader factors. For example, each of the factors in the Five Factor Model (FFM; Costa \& McCrae, 1992b) contain six facets; the factor of extraversion contains facets such as warmth, gregariousness, and assertiveness. Murphy and Dzieweczynski (2005: 345) concluded that any personality inventory that utilizes the FMM factors is almost always a "fairly poor predictor" of job performance. Very few studies investigating the personality and job performance relationship have examined an extensive list of facets and no single study has included more than 30 facets. Most studies select no more than 12 facets each (for a good summary, see Judge et al., 2013).

Much research has focused on facets that fall outside the FFM (Ashton, Lee, \& Son, 2000; Jackson, Ashton, \& Tomes, 1996; Jackson, Paunonen, Fraboni, \& Goffin, 1996; Lee \& Ashton, 2004; Lee, Ashton, Hong, \& Park, 2000; Petrides, 2009). There is also substantial evidence of facet-level traits which are not found within the FFM, but which are important to job outcomes. For example, Paunonen and Jackson (2000) reanalyzed data from Saucier and Goldberg (1998) and found that trait adjectives such as devout, deceptive, ethical, frugal, and conservative fell outside the FFM. Even a passing consideration of these traits quickly reveals that they could be especially important to explaining workplace behaviors. Moreover, these traits provided incremental validity over and above the FFM in relation to 19 criteria across samples from Canada, England, Germany and Finland (Paunonen, Haddock, Forsterling, \& Keinonen, 2003).

The FFM does not exhaust the description of the personality domain (McCrae \& John, 1992) and Hough (1992: 139) suggested that constructs "above and beyond" the Big Five may be important if the goal of using personality variables is prediction rather than description. Block 
ID13292

(1995: 188) maintained that a list of personality constructs should be "sufficient in number so that the personalities of individuals and the dynamics of behaviors can be represented in articulated ways and discriminating explanations and predictions may be formulated". The usefulness of a model is an important aspect of its validity, so if the traits in the model are found to be significant predictors of a variety of important life outcomes, then the traits themselves are useful, regardless of how many traits there might be. The qualities of facet scales - their concreteness and specificity - are often regarded as more scientifically desirable than the broad factor scales (Wiggins, 1992). A single personality inventory, with an extensive list of narrow facets, can create a meaningful theoretical framework from which trait and work-behavior associations can be established.

\section{Work-personality}

There is a considerable body of evidence showing that variability in personality may be situation dependent (e.g. Fleeson \& Law, 2015; Sherman, Rauthmann, Brown, Serfass, \& Jones, 2015). Although there has been progress in developing taxonomies of situations such as DIAMONDS (Rauthmann, Gallardo-Pujol, Guillaume, Todd, Nave, Sherman et al., 2014; Rauthmann \& Sherman, 2016) or CAPTION (Parrigon, Woo, Tay, \& Wang, 2017), together with a number of investigations (Geukes, Nestler, Hutteman, Kuefner, \& Back, 2017; Judge et al., 2013; Minbashian, Wood, \& Beckmann, 2010), there does not appear to be an agreed framework to determine which features of situations influence personality expression. Nevertheless, despite using different measures, each of the studies above shows that personality expression is dependent on situational characteristics.

In a series of situational-specific studies related to the workplace, "work-personality" was shown to be a better predictor of job satisfaction than either overall-personality or home- 
ID13292

personality (Heller et al., 2009), and a better predictor of work-related criteria than over-all personality (Bowling \& Burns, 2010). Since personality can be defined as, "consistent and enduring individual differences in ways of thinking, feeling and acting" (Costa \& McCrae, 2008: 180), work-personality was defined as, "characteristic patterns of thoughts, feelings and behaviors at work" (Heller et al., 2009: 1055). Therefore, an inventory expressly developed to measure work-personality is likely to be a strong predictor of work-related criteria.

\section{Observer ratings of personality}

Personality can be rated by the self or by observers; in personality research, self-reports are more commonly used than observer-reports (Connelly \& Ones, 2010; Vazire, 2006). Hogan's (1996) socio-analytic theory is one explanation for the difference between what selfratings and observer-ratings actually measure. Hogan distinguished between a person's selfperception as their 'inner personality' and a person's public perception or social reputation as the 'outer personality'. The inner personality incorporated information about thoughts, feelings and intentions that are less visible to the observer. Oh, Wang and Mount (2011: 764) asserted that inner personality and outer personality are not necessarily the same, although they are "related to some degree". Funder (1995) suggested that some traits might be more observable than others, and Vazire (2010) proposed that traits might be categorized as more 'inner' or 'outer', and we might even have blind spots in how we view ourselves. Therefore, some traits might be more accurately rated by an observer rather than the self.

Traditionally, the inner personality was considered to be the true personality; it therefore followed that self-reports would be most accurate. Accuracy of observer ratings is often measured by how closely they align with self-ratings; indeed, self-observer agreement is commonly reported in empirical research that investigates both self- and observer-ratings of 
ID13292

personality (e.g. Connelly \& Ones, 2010; McCrae, Costa, Martin, Oryol, Rukavishnikov, Senin et al., 2004; Mottus, McCrae, Allik, \& Realo, 2014; Vazire, 2010). But accuracy has also been conceptualized as the predictive ability of the rating. It has been argued that the prediction of behavior is the ultimate criterion for accuracy (Funder \& West 1993; Connelly \& Ones 2010). If behavioral prediction is the best measure of accuracy, then prediction of job performance would be the most important measure of accuracy on which to develop a model of work-personality.

When predicting job performance, researchers regularly report low amounts of variance explained when utilizing self-report questionnaires to predict overall job performance (e.g. Barrick et al., 2001; Judge et al., 2013). It is well known that conscientiousness is the best predictor of overall job performance, but even so, Judge et al.'s (2013) meta-analysis showed that the observed correlation of self-reported conscientiousness with overall job performance only explained $4.4 \%$ of the variance in overall job performance. In contrast, higher amounts of variance explained are found when using observer-ratings of personality. A meta-analysis by Connelly and Ones (2010) showed the observed correlation of observer-rated conscientiousness with overall job performance explained $6.9 \%$ of the variance in overall job performance.

Further, Oh et al. (2011) showed not only that the validities of observer ratings were higher than self ratings, but also that the ratings of observers improved incremental validity over both selfratings and general mental ability. Together, this suggests that when the desired result is the ability to predict job performance, work-personality might be best rated by an observer, rather than the self.

\section{Measuring job performance}

While most empirical studies investigating personality and job performance include some measure of overall job performance, there is no consensus on the definition of this term or its 
ID13292

measurement. Campbell, McHenry, and Wise (1990) described job performance as the observable behaviors relevant to the organization's goals. Motowidlo, Borman, and Schmit (1997: 72) defined job performance as "the aggregated value to the organization of the discrete behavioral episodes that an individual performs over a standard interval of time". Sometimes discrete behaviors are measured and then summed to create a score of overall performance, whereas other studies include a single item asking raters to judge the overall job performance of the employee. Summarizing the extensive variation in measurement, Deadrick and Gardner (2008: 133) observed that "after more than 70 years of research, the 'criterion problem' persists, and the performance-criterion linkage remains one of the most neglected components of performance-related research".

Some researchers have addressed the criterion problem by working towards development of a model of job performance. Bartram (2005) developed a hierarchical model of eight job competencies that are generalizable across jobs. He further demonstrated that personality traits are differentially predictive of eight narrow competencies, and that using narrow measures of competencies showed higher concurrent validities than using an overall measure of job performance (Bartram, 2005). A meta-analysis (Rojon, McDowall, \& Saunders, 2015) which examined personality as predictors of eight narrow job components based on Campbell and colleagues' (1993) performance taxonomy found similar results.

Yet there remains a divide between research and practice. Most scholarly research focuses on broad personality traits that are predictive of a broad measure of overall job performance, while most practitioners are interested in specific traits that are predictive of specific jobs. Some researchers have suggested that further research into broad measures should be curtailed, recommending instead an approach that includes specific predictor-criterion 
ID13292

pairings (Bartram et al., 2010). Yet to date, very little research has explored outcomes based on the narrow job requirements regularly utilized by practitioners (Hughes \& Batey, 2017).

To address this gap, we turned to innovative techniques suggested in the literature that indicated incremental improvements in personality predicting job performance. We sought to study a large number of facets, more than just the 30 facets included in the FFM. Not finding a suitable inventory, we therefore started this study by developing a comprehensive inventory for work-personality facets. Since observer-ratings have shown improved validities when predicting job performance, we then sought to examine the relationship of all facets, using observer-ratings, with narrow job performance outcomes, which would also be useful to practitioners. So we conducted correlations of each observer-rated work-personality facet with nine job performance outcomes. This was followed by selecting few personality facets for each outcome, and then exploring the combined validities of these facets as predictors of each job performance measure.

One way to investigate facets outside the FFM space is to locate and measure a few specific traits. For this study, we took a different approach, seeking to find the personality model with the largest number of facets with the intention of measuring all facets simultaneously. Most personality inventories contain 30 facets or fewer (e.g. Ashton \& Lee, 2008; Costa \& McCrae, 1992b; Tellegen, 1995). Some researchers contend that DeYoung et al. (2007) identified 75 facets, yet close inspection reveals two FFM inventories (the NEO-PI-R and the AB5C) were investigated, thus duplicating the facets included in the study.

We located the 11+ Factor Model (Irwing \& Booth, 2013) which has 71 personality facets; it was derived from empirical research which performed the largest ever item level investigation, based on combined data from eleven inventories. The eleven inventories included: 16PF (Conn \& Rieke, 1994), 6FPQ (Jackson, Paunonen, \& Tremblay, 2000), CPI (Gough \& 
ID13292

Bradley, 2002), HEXACO (Lee \& Ashton, 2004), JPI (Jackson, 1994), MPQ (Tellegen \& Waller, 2008), NEO-PI-R (Costa \& McCrae, 1992b), IPIP Machiavellianism scale (Goldberg, 1999), Need for Cognition scale (Cacioppo \& Petty, 1982), Right-Wing Authoritarianism scale (Altemeyer, 1981), and the Social Dominance Orientation scale (Pratto, Sidanius, Stallworth, \& Malle, 1994). This model displayed strong psychometric properties (Booth, 2012) and contained the most comprehensive list of facets of any extant personality model. However, this model did not yet have an inventory associated with it, as the scales originated from multiple commercial inventories. Thus, the first aim of this research was to develop an inventory to measure the facets of the 11+ Factor Model within the context of the workplace.

Research Aim 1: To develop an inventory to measure work-personality facets based on the facets of the 11+ Factor Model.

An inventory expressly developed to measure work-personality is likely to be a strong predictor of work-related criteria. If the prediction of behavior is the ultimate criterion (Funder \& West, 1993), and observer ratings are more predictive of job performance than self-ratings (Connelly \& Ones, 2010; Oh et al., 2011), then observer's ratings are the most useful for developing a model of work-personality. Use of observer ratings is supported by a rich historical tradition of development in personality models. Early empirical studies of personality often started their analyses with observer-ratings of personality (e.g. Norman, 1963; Tupes \& Christal, 1961) then cross-validated the structure of personality using an independent dataset, either a second set of observer-ratings (e.g. D'Andrade, 1965; McCrae \& Costa, 1987) or self-ratings (e.g. Fiske, 1949; Passini \& Norman, 1966). The analysis for this study will follow such precedents. 
ID13292

This research seeks to improve the explanatory power of personality when predicting job performance, and using narrow measures on both sides of the equation have been shown to improve predictive validities (Bartram et al., 2010; Tett et al., 2003). Therefore once a workpersonality inventory is developed, investigation will continue using the newly measured facets and consider their relationship with narrow measures of job performance. Job competency models have become a powerful tool for assessing job performance (Bartram, Robertson, \& Callinan, 2002) and some models contain both broad and narrow measures (e.g. Bartram, 2006; Campbell et al., 1993). The next step then will be to investigate the correlations of the narrow facets with narrow job performance measures.

Research Aim 2: To investigate the correlations of observer-rated work-personality facets with narrow measures of job performance.

We will then investigate the amount of variance in job performance than can be explained by a combination of select facets. Combining facets in this way is similar to using compound traits, which is a combination of traits that do not necessarily covary, but when combined maximize the prediction of specific criterion constructs (Hough \& Schneider, 1996). Using compound traits in a predictive validity analysis is a rising trend in personality psychology (Darr \& Kelloway, 2016). Purposefully built assessments could contain various personality facets which can be combined to yield a single composite score (O'Neill \& Paunonen, 2013). For example, if leadership effectiveness was the criterion of interest, the facets of assertiveness (extraversion), achievement striving (conscientiousness), and ideas (openness) may be combined to form a compound personality measure that could be highly predictive of the outcome criterion. Also called multifaceted personality predictors (Hogan \& Foster, 2013) or criterionfocused occupational personality scales (Ones \& Viswesvaran, 2001), some examples of 
ID13292

personality compounds that have been found to be useful for predicting their intended criterion construct are workplace safety (Hogan \& Foster, 2013), integrity (Ones, Viswesvaran, \& Schmidt, 1993), and employee reliability (Hogan \& Hogan, 1989).

Research Aim 3: To investigate the validities of combined observer-rated work-personality facets predicting narrow measures of job performance.

\section{METHOD}

\section{Participants and Procedures}

Organizations world-wide were invited to participate in the study through advertisement on LinkedIn, email, personal contacts, and local networking events. Meaningful contact was established with the Human Resource (HR) directors at three different organizations within the UK, two of which agreed to participate. Advertising for the study was performed within each organization by the HR department, via email distribution and postings on the organization's intranet. Employees interested in participating were required to nominate two co-workers to provide observer-ratings of personality and a manager to provide job performance ratings. Snowballing was also used; co-workers who were nominated as other-raters were also invited to participate as ratees. Participation in the project was entirely voluntary and was promoted within the organizations as a self-development opportunity whereby ratees would receive a personality report for their participation in the study.

The personality questionnaire was designed with a three-form planned missing data design (Graham, 2012) such that at least $66 \%$ of the sample responded to each question. Three forms of the personality questionnaire were developed for self-raters. The instruction on the three forms was then slightly modified to be appropriate for observer-ratings, and separate 
ID13292

questionnaires were created. In order to protect anonymity of the participants, the organization's HR team handled all inquiries about the study and sent out links to the online questionnaires. The HR team assigned one of the three forms, and an ID code to the ratee, then corresponding hyperlinks were sent to the ratee and co-workers. Managers were sent a separate link to a questionnaire where they rated the ratee's job performance. Observer and manager ratings identified their ratee by entering a pre-assigned ID code into the questionnaire.

The study comprised 1,041 participants (331 self-raters, 469 co-workers, 241 managers) who were employed in the UK $(92 \%$ in a police organization, $8 \%$ in a music college). The data was collected separately from the two organizations, but to improve sample size, the data was combined. The differences in these organizations should be considered when interpreting results. The police organization is likely to attract employees who prefer structure, order, and are highly dependent on their partners. The music college is likely to attract employees who are highly creative, spontaneous, and more likely independent. Concerning the factorial validation of the facets, there should be no risk in combining these samples. But rather, these two organizations are complimentary, possibly reducing the range restriction that would have resulted from using such a homogenous sample as a police organization. Conversely, there may be issues with combining the results of the job performance measures. Most job performance measures are transferrable skills and will look similar in most jobs, such as analyzing, presenting, or organizing. But a few of these measures, such as creating and adapting, may be interpreted differently in a music college and a police organization.

Forty-nine percent of the participants were female and the mean age was 41 . Co-workers were well suited to provide observer ratings of personality, as most (83\%) reported they 
interacted with their ratee several times per week or more. Eighty-six percent of managers reported they had worked with their ratee for five years or less.

\section{Measures}

Personality. Personality facets were based on the facets of the 11+ Factor Model, where 71 facets are grouped within 11 factors. The factor of assertiveness comprised the facets of assertiveness, non-judgementalism, dominance, social confidence, forgiveness, and stubbornness. Social astuteness was composed of narcissism, deviousness, altruism and empathy. Sociability included sociability, self-reliance, people versus things, dependent, affability, social boldness, leadership, social dependence, and conformity. Aggression comprised excitement seeking, harm avoidance, and alienation. Positive affect included optimism, surgency, vigor, seriousness and enthusiasm. Externalizing included emotional reactivity, negativity, callousness, lack of remorse, conflicted relationships, nervous anxiety, and inferiority. Conscientiousness was composed of planfulness, practical versus imaginative, impulse control, caution, orderliness, detail consciousness, self-discipline, spontaneity, competence, integrity, and unconventionality. Prejudice included traditionalism, intolerance, liberalism, punitiveness, complexity, and openness-to-change. Resilience included fearfulness, achievement, diligence, sensitivity, risk-taking, and tolerance. Openness was composed of intellectual curiosity, understanding, aesthetic interests, cognitive interests, creativity, absorption, fantasy, and perseverance. Lastly, the factor of internalizing included the facets of anxiety, worry, depression, rumination, anger, and self-consciousness.

To meet the statistical assumptions required for this inventory, a minimum of two items are required per facet, although more is better (Kenny, 1979). Theoretically, the construct domain of a narrow facet is small, so only a few items are needed. Therefore, three items were 
ID13292

selected from the International Personality Item Pool (IPIP; Goldberg, 1999) to measure each facet. Participants were instructed to rate how much they agreed or disagreed that each item described the personality of the ratee "while at work" $(1=$ strongly disagree, $7=$ strongly agree $)$. For example, items included takes care of their own affairs and makes people feel welcome. Job Performance. Job performance measures were based on the Universal Competency Framework (Bartram, 2006). The outcomes were measured as: leading, supporting, interacting, analyzing, creating, organizing, adapting, enterprising and overall job performance. The first eight measures were taken from the inventory which measured Bartram's (2005) Great Eight job competencies, and were measured with four to six items each. Overall job performance was created by summing all 40 items in the inventory. Managers rated how much they thought each item was an area of strength for the ratee $(1=$ significant development needed, $5=$ outstanding strength). For example, items included staying calm under pressure and adhering to defined work methods. Scale reliabilities have been shown to possess good internal consistency with manager ratings, ranging from .90 for cooperating to .96 for analyzing (Bartram, 2007).

Reliabilities and correlations between study variables are presented in Table 1.

Insert Table 1 about here.

\section{RESULTS}

\section{Inventory Development}

The first research aim was to develop a work-personality inventory based on the facets of the 11+ Factor Model. Using confirmatory factor analysis (CFA), eleven measurement models were specified a priori based on the facet groupings of the 11+ Factor Model. The facets were 
ID13292

grouped according to the broad factor structure of the 11+ Factor Model, such that each model reflected all the facets under one broad factor. Initial models were considered as the first step of a model generating stage, whereby models that did not fit the given data were modified and retested with the same data. Once a model fit well and interpretation was meaningful (Joreskog, 1993), the model was cross-validated using two independent datasets. Cross-validation was strictly confirmatory; models were either accepted or rejected. Cross-validation is a powerful approach for evaluating models (Millsap \& Meredith, 2007) and ensured the results did not capitalize on chance (Joreskog, 1971). To perform cross-validation, the co-worker responses were randomly divided into Sample 1 and Sample 2. Sample 3 contained all self-ratings.

Facets were evaluated in two ways: model fit and factorial validity. Close model fit was determined by values $\geq .90$ for the Comparative Fit Index (CFI) and Tucker-Lewis Index, (TLI) and values $\leq .08$ for the Root Mean Square Residual (RMSEA) (Hu \& Bentler, 1999; Schermelleh-Engel, Moosbrugger, \& Muller, 2003). Factorial validity was evaluated with convergent validity (scale factor loadings must be $>.30, p<.05$ ) and discriminant validity (facet correlations $<.95,95 \%$ CI) cut-offs. Mplus 8.0 (Muthén \& Muthén, 1998-2015) with the Weighted Least Squares Means and Variances adjusted (WLSMV) estimator was used for all analyses.

Convergent and discriminant validity cut-offs led to 20 facets either being combined with another facet or removed, resulting in 11 models comprised of 51 facets. These 11 models were cross-validated in a strictly confirmatory way on two datasets. Most models provided close fit to all three datasets; fit statistics for each model are presented in Table 2.

Insert Table 2 about here. 
ID13292

Within these 11 models, all facets exhibited convergent and discriminant validity. With Sample 1, factor loadings ranged from .35 to $.99(p<.001)$ with a mean of .70. Samples 2 and 3 showed similar results. The mean factor loading was .70 with Sample 2 and .64 with Sample 3. Facets exhibited discriminant validity with facet intercorrelations that ranged from 0.01 (selfconsciousness with rumination) to 0.85 (self-discipline with detail consciousness). Based on model fit and factorial validity, 51 facets satisfactorily cross-validated using data from both selfratings and observer-ratings ${ }^{1}$. This evidence suggests that at least 51 facets are required for a comprehensive model of work-personality. A list of the 51 facets can be found in the left-hand column of Table 3 .

Insert Table 3 about here.

\section{Correlations of work-personality facets with narrow job performance outcomes}

The newly developed inventory provided the personality variables for investigation in the remainder of this study. We turn now to consider the correlations of the 51 work-personality facets with each of the nine job performance outcomes. Correlations between all 51 observerrated personality facets and 9 manager-rated job performance measures are shown in Table 3. Correlations ranged from 0 to 0.44 .

The personality facets of integrity, leadership, self-discipline and empathy tended to show the highest correlations across most of the Great Eight competencies. Integrity showed significant correlations $(p<.01)$ with every criterion: leading $(.32)$, supporting $(.23)$, interacting (.31), analyzing (.44), creating (.42), organizing (.22), adapting (.41), enterprising (.26), and

\footnotetext{
${ }^{1}$ A complete list of factor loadings of all 275 items on the 51 facets across the three samples can be obtained by request from the first author.
} 
ID13292

overall job performance (.39). Leadership showed significant correlations $(p<.05)$ with seven criteria: leading (.34), interacting (.37), analyzing (.44), creating (.35), organizing (.21), adapting (.27), and overall job performance (.35). Self-discipline showed significant correlations $(p<.05)$ with seven criteria: leading (.31), analyzing (.37), creating (.37), organizing (.22), adapting (.23), enterprising (.18), and overall job performance (.31). Empathy showed significant correlations $(p$ $<.05)$ with seven criteria: supporting (.35), interacting (.36), analyzing (.31), creating (.26), organizing (.22), adapting (.28), and overall job performance (.28).

Most criterion measures had approximately five personality traits where the correlations were greater than .3 and significant $(p<.001)$. The top five trait-performance correlations for each competency are shown in bold Table 3. Across the nine criterion variables, nineteen unique facets comprised the top five trait-performance correlations. Of those nineteen, nine facets were predictive of more than one competency: integrity (7), leadership (6), self-discipline (5), empathy (5), enthusiasm (3), planfulness (3), conflicted relationships (3), harm avoidance (2) and achievement (2).

\section{Validities of work-personality facets when predicting job performance}

The final research aim was exploratory in nature, seeking to identify which of the 51 facets might be important to the nine job performance outcomes. This was examined by conducting a stepwise regression using a structural equation modelling (SEM) framework. Adopting a strategy proposed by Green and colleagues (Green \& Babyak, 1997; Green, Thompson, \& Poirer, 2001), we used a two-step process whereby variables were added to a model in the process of optimizing fit, then tested, and then deleted if they did not contribute significantly to explained variance. 
ID13292

Due to the extremely high number of possible combinations of 51 predictors and 9 outcome variables, it was practically necessary to limit the number of SEM analyses to a manageable amount. The selection of predictor variables was based on empirical and practical criteria. Many alternate strategies are possible that could have guided the selection of the predictor variables. For example, traits could have been selected based on theoretical expectations of which traits are the best predictors of each outcome. Alternatively, traits could have been selected theoretically based on which are best for an observer to rate, as suggested by Funder's (1995) Realistic Accuracy Model or Vazire's (2010) Self-Other Knowledge Asymmetry model. These two options are problematic because there is very little published support that is relevant to this study. There is an especial paucity of published work using observer ratings of facet-level traits as predictors of job performance. By contrast, a selection of traits from across all factors could have been selected. This would have ensured a sampling of traits were tested but provides no assurance that strong concurrent validities might be found. Due to concerns about low validities of personality traits as usually seen in the literature, and a major goal of this paper is to identify high validities, it was decided to limit the analysis to the traits with the highest correlations. Therefore, predictor facets were selected based on the strength of the trait-performance correlation and were limited to the top five correlates (see Table 3). Cross-validation with a second data set would ensure the results did not capitalize on chance (Joreskog, 1971).

Modelling began with the strongest personality correlate as the first predictor variable of the job performance outcome, using the Sample 1 dataset. Additional facets were added one at a time, in order of strength of correlation. This process continued until facets stopped contributing importantly to the model, which was typically attained after three facets. 
ID13292

Based on this method, each model varied in the number of facets added in the stepwise regression, but no model contained more than three facets. The personality facets for each regression model are found in the left-hand column of Table 4. Each model was cross-validated with a second-set of observer ratings (Sample 2). All models provided close fit to the Sample 1 datasets and most models showed close fit to the Sample 2 dataset. Table 5 provides fits statistics for each model.

Results indicate that ten personality facets (integrity, leadership, harm avoidance, empathy, social dependence, complexity, self-discipline, orderliness, anxiety and enthusiasm) may be particularly important for the prediction of job performance. Across the nine models, four facets appear more than once: integrity (6), leadership (5), harm avoidance (2) and empathy (2). Integrity was found to be an important predictor of leading, analyzing, creating, adapting, enterprising, and overall job performance.

Variance explained for each model is shown in Table 4. With Sample 1 data, total variance explained was statistically significant $(p<.05)$ for all models, and ranged from $15 \%$ (enterprising explained by integrity, harm avoidance and enthusiasm) to $31 \%$ (analyzing explained by integrity and leadership). With Sample 2 data, statistically significant results ranged from $13 \%$ (enterprising explained by integrity, harm avoidance and enthusiasm) to $30 \%$ (supporting explained by empathy and complexity). Results suggest that only two or three workpersonality facets, when rated by observers, can explain as much as $30 \%$ of the variance in narrow job performance measures.

Insert Tables $4 \& 5$ about here. 


\section{DISCUSSION}

In this large-scale study we explored observer-ratings of narrow personality facets predicting narrow measures of job performance. We started this study by developing an inventory for work-personality facets, and results suggest that at least 51 personality facets can describe work-personality. We then examined the correlations of these 51 facets based on observer-ratings, with 9 job performance outcomes. The personality facets of integrity, leadership, self-discipline and empathy tended to show the highest correlations across most of the Great Eight competencies. Lastly, we selected a few facets as predictors of each outcome, and found that combining two or three facets can explain as much as $30 \%$ of the variance in narrow job performance measures. Each of these findings will be discussed more fully in turn.

The evidence from this study suggests that at least 51 facets are required for a comprehensive model of work-personality. The model generating process resulted in a satisfactory fit for 51 facets: all models showed at least moderate fit to three datasets, and each facet exhibited convergent and discriminant validity. As this was the first attempt to develop an inventory for this set of facets, it is not surprising that some CFA models required minor modifications and some of the original facets were removed. While the modification process was limited by strict criteria, it could have been improved by a more robust expert review when selecting items or implementing an additional step to rewrite poorly performing items. However, there is general agreement that CFA combined with cross-validation represents a powerful approach for assessing measurement models (Millsap \& Meredith, 2007). Therefore crossvalidation using two datasets, as conducted in this study, provides persuasive evidence for the generalizability of these findings. 
ID13292

Of these 51 facets, more than half are not accounted for in the FFM. While many researchers have proposed additional factors and facets beyond those accounted for in the FFM (e.g. Ashton \& Lee, 2008; Irwing \& Booth, 2013; Paunonen \& Jackson, 2000), this is the first study to provide empirical evidence for an extensive list of unique facets. The results of this study suggest the 51 facets are accurate constructs, therefore suggesting that a model of workpersonality should contain at least 51 facets as described herein.

Turning to the results of the correlation analysis, the correlations of each facet with each measure of job performance vary considerably. Some, but not all facets show strong correlations. This conforms with other published research on facets and job performance (Judge et al., 2013), although the range is broader than is typically reported for self-ratings at the facet level.

The personality facets of integrity, leadership, self-discipline and empathy tended to show the highest correlations across most of the Great Eight competencies. The importance of integrity and self-discipline is not surprising as both are facets of conscientiousness, and previous research has consistently shown a relatively strong correlation of conscientiousness with job performance. However, integrity is rarely considered as a unique facet (it is not included as a facet in the FFM) and is sometimes considered a composite of factors (Catano, O'Keefe, Francis, \& Owens, 2018) or a behavior to be measured with an integrity test (Schmidt \& Hunter, 1998). Yet in this case, as a narrow personality facet, integrity showed some of the highest correlations across multiple job performance measures, ranging from .22 with organizing to .44 with analyzing. Not all facets of conscientiousness appeared to be important to each measure of job performance, but in addition to integrity, the facet of self-discipline frequently showed strong correlations; the highest with analyzing and creating $(r=.37)$. The importance of leadership and 
ID13292

empathy might be particularly influenced by the sample in this study, which largely was derived from a police organization. Leadership is characterized by assertiveness with others, while those high on empathy take a strong interest in other people's problems. Both of these traits are particularly important to performing well in police organizations.

The last aim of this study was to identify a combination of facets that are strongly predictive of the Great Eight competencies. The facets selected for the regression models were likely to capitalize on chance, so cross-validation with a second sample provided a strong test of the generalizability of the results (Joreskog, 1971). With Sample 1, variance explained ranged from $15 \%$ to $31 \%$. With Sample 2, variance explained ranged from $6 \%$ to $30 \%$.

Starting with the criterion measure of overall job performance with the cross-validated model (Sample 2), 10\% of the variance was explained collectively by the facets of integrity and leadership. This variance explained is slightly higher than those reported in published metaanalyses of the relationship between observer-rated personality and overall job performance (Connelly \& Ones, 2010; Oh et al., 2011). Thus these results suggest that measuring observerrated personality traits at the facet level, and combining the predictive power of selected facets, can provide higher concurrent validities than broad factors of personality, when predicting overall job performance.

Furthermore, all the statistically significant results of the cross-validated models evidenced superior variance explained than the model predicting overall job performance. Together, integrity, harm avoidance and enthusiasm accounted for $13 \%$ of the variance in enterprising. Integrity and anxiety explained $14 \%$ of the variance in adapting. Leadership and empathy accounted for $14 \%$ of the variance in presenting. Integrity, leadership and social 
ID13292

dependence accounted for $21 \%$ of the variance in leading. Empathy and complexity explained $30 \%$ of the variance in supporting.

These findings can be explained by similar research which also showed that narrow measures of job performance evidenced higher validities than a broad measure of overall job performance. For example, Bartram (2005) examined the validities of two facets explaining each of the Great Eight competencies when using self-report data. The models with the most variance explained were: leading explained by the facets of controlling and decisive (7.1\%), enterprising explained by the facets of achieving and competitive (7.5\%), and interacting explained by the facets of socially confident and outgoing (7.6\%). Further, a meta-analysis published by Rojon and colleagues (2015) examined self-report measures of personality factors as predictors of eight narrow job components based on Campbell et al.'s (1993) performance taxonomy. The models with the most variance explained for the narrow criteria measures were: the factor of conscientiousness explaining personal discipline (9.6\%), written and oral communication explained by the factor of agreeableness $(10.2 \%)$, and personal discipline explained by the factor of openness $(16.0 \%)$. Thus taken together, the amount of variance explained shown by some of the models in this study are higher than what is usually seen in the literature with self-ratings of personality. These results indicate that when using observer-rated work-personality facets, selecting and combining the correct facets can improve the validities when predicting narrow job performance measures.

\section{Theoretical and Practical Implications}

The evidence from this study suggests that at least 51 facets are required for a comprehensive model of work-personality. These results have theoretical implications, suggesting that researchers should work to create consensus on a model of personality that 
contains a much longer list of facets than that which is usually contained within most of the popular personality models. For example, the FFM may be the most widely researched model of personality traits, but researchers also agree that it does not exhaust the description of the personality domain. Returning to Block (1995), we are reminded that we need not unnecessarily limit the quantity of constructs in a model, but rather, it is important to consider the usefulness of those constructs. Many traits beyond the FFM were studied here and found to be important to the prediction of job performance. Therefore, these traits are useful constructs, and should be included in a comprehensive model of personality.

Focusing on particular personality facets, ten observer-rated facets (integrity, leadership, harm avoidance, empathy, social dependence, complexity, self-discipline, orderliness, anxiety and enthusiasm) were found to be useful predictors of the Great Eight competencies. Integrity was found to be an important predictor in six regression models (leading, analyzing, creating, adapting, enterprising, and overall job performance). Taken together, this finding suggests that researcher and practitioners interested in predicting the Great Eight competencies should consider measuring these ten facets, and that integrity is a crucial trait that should nearly always be included. Integrity is often considered as a composite of higher-order factors, but in this study, it's been modeled as a specific facet and found to be highly correlated with, and predictive of, multiple aspects of job performance. This has implications for how we might theoretically understand, and therefore model, the trait of integrity.

Furthermore, evidence from this study indicates that only two or three work-personality facets, when rated by observers, can explain as much as $30 \%$ of the variance in narrow job performance measures. We see here that combining the correct facets can lead to very high predictive validities - improving explanatory power and usefulness of personality traits in 
ID13292

predicting job performance. This amount of variance explained is very useful in a personnel selection context, to which these findings could have practical application. For example, once the required facets have been identified, then personnel selection processes only need to measure those few specific traits. Observer-ratings could be obtained by incorporating personality questions into the referee process, in the format of a brief personality questionnaire or a structured interview.

\section{Limitations and Future Research}

Limitations of this study suggest directions for future research. First, most personality facets we examined were measured with only three items. This was a pragmatic choice due to the extensive length of the personality questionnaire. Three items ensured factor analysis could be conducted, but theoretically, the total domain corresponding to each construct may not have been fully sampled. Further, some facets were removed or combined during the CFA process. Additional research could investigate these facets, perhaps by re-writing the poorly performing items to confirm whether they should be included in a model of work-personality. As this was a first attempt to build such an inventory, future research could work to provide a more comprehensive coverage of work-personality facets.

Second, we selected the facets for the regression models empirically, based on the results of the correlation analysis. A limitation of this process is that validity results are likely to capitalize on chance. Cross-validation improved the rigor of this study to ensure the results are useful and generalizable. Even so, alternate decisions could be made at this point, and provide avenues for future research. As previously mentioned, traits could have been selected based on theoretical expectations of which traits are the best predictors of each outcome, or chosen by which traits are best for an observer to rate. It is likely that some traits that are highly predictive 
ID13292

of job performance were not included in the regression models in this study. Future research could work to further identify which work-personality facets are important to job performance.

Finally, $90 \%$ of the study participants were from a UK police organization. This does not limit the generalizability of the CFA results, as there is no reason to believe that analysis of personality structure was influenced by the sample or the process. However, it might limit the generalizability of the correlations and validities to the wider working population. It is possible that police organizations attract people with certain traits or values, which might restrict the range in the ratings of both personality and job performance. Also, it is likely that the values of a UK police organization are different from those espoused from a police organization of a thirdworld country for example. Some of the ten facets found to be predictive of the Great Eight competencies may be specific to this sample. The facets of integrity, self-discipline and orderliness are all facets of conscientiousness. According to research at the factor level, conscientiousness is always the strongest predictor of job performance, regardless of whether it is measured by self-raters (Barrick et al., 2001) or observers (Connelly \& Ones, 2010). Therefore, these three facets are likely generalizable across all jobs. The remaining seven facets (leadership, harm avoidance, empathy, social dependence, complexity, anxiety and enthusiasm) may show correlations specific to this sample. Cross-validation indicates these results are reliable, which suggests that concurrent validities can be generalized to other UK police organizations. But future research should investigate work-personality in a variety of industries, such as banking, retail, or manufacturing, to further examine the concurrent validity of facets and broaden the application of work-personality. 


\section{Conclusion}

Researchers agree that the FFM does not exhaust the description of the personality domain. The evidence from this study suggests that at least 51 facets are required for a comprehensive model of work-personality; researchers should continue to work out a model of personality that contains a much longer list of facets than that which is usually contained within most of the popular personality models. Narrow personality measures are important; continuing the traditional use of factors results in the loss of specific variance in the underlying facets. The same problem occurs on the criterion side - an overall measure of job performance loses the specific variance of its components. Thus the level of specificity of measurement is critical when specific variance is most predictive of the criterion of interest, as is the case in most applied scenarios. As shown here, only two or three work-personality facets, when rated by observers, can explain as much as $30 \%$ of the variance in narrow job performance measures. To improve validities of personality predicting job performance, we suggest the way forward is to utilize observer-ratings and narrow measures on both sides of the equation. 
ID13292

\section{REFERENCES}

Altemeyer, R. A. 1981. Right-wing authoritarianism. Winnipeg: University of Manitoba Press. Ashton, M. C., Lee, K., \& Son, C. 2000. Honesty as the sixth factor of personality: Correlations with Machiavellianism, primary psychopathy, and social adroitness. European Journal of Personality, 14(4): 359-368.

Ashton, M. C. \& Lee, K. 2008. The HEXACO Model of personality structure. In G. J. M. Boyle, G. \& D. H. Saklofske (Eds.), The SAGE Handbook of Personality Theory and Assessment. Thousand Oaks, CA: SAGE Publications.

Barrick, M. R. \& Mount, M. K. 1991. The Big Five personality dimensions and job performance: A meta-analysis. Personnel Psychology, 44(1): 1-26.

Barrick, M. R., Mount, M. K., \& Judge, T. A. 2001. Personality and performance at the beginning of the new millennium: What do we know and where do we go next? Personality and Performance, 9(1/2): 9-30.

Bartram, D., Robertson, I. T., \& Callinan, M. 2002. Introduction: A framework for examining organizational effectiveness. In I. T. Robertson, M. Callinan, \& D. Bartram (Eds.), Organizational effectiveness: The role of psychology: 1-10. Chichester, United Kingdom: Wiley.

Bartram, D. 2005. The Great Eight Competencies: A criterion-centric approach to validation. Journal of Applied Psychology, 90(6): 1185-1203.

Bartram, D. 2006. The SHL Universal Competency Framework. Surrey: Thames Ditton.

Bartram, D. 2007. Increasing validity with forced-choice criterion measurement formats. International Journal of Selection and Assessment, 15(3): 263-272.

Bartram, D., Warr, P., \& Brown, A. 2010. Let's focus on two-stage alignment not just on overall performance. Industrial and Organizational Psychology-Perspectives on Science and Practice, 3(3): 335-339.

Block, J. 1995. A contrarian view of the five-factor approach to personality description. Psychological Bulletin, 117(2): 187-215.

Booth, T. 2012. A Review of the Structure of Normal Range Personality. University of Manchester, Manchester, UK.

Bowling, N. A. \& Burns, G. N. 2010. A comparison of work-specific and general personality measures as predictors of work and non-work criteria. Personality and Individual Differences, 49: 95-101.

Campbell, J. P., McHenry, J. J., \& Wise, L. L. 1990. Modelling job performance in a population of jobs. Personnel Psychology, 43: 313-333.

Campbell, J. P., McCloy, R. A., Oppler, S. H., \& Sager, C. E. 1993. A theory of performance. In N. Schmitt \& W. C. Borman (Eds.), Personnel Selection in Organizations. San Francisco: Jossey Bass.

Catano, V. M., O'Keefe, D. F., Francis, R. E., \& Owens, S. M. 2018. Construct-based approach to developing a short, personality-based measure of integrity. International Journal of Selection and Assessment, 26(1): 75-92.

Conn, S. R. \& Rieke, M. L. 1994. The 16PF fifth edition technical manual. Champagne, IL: Institute for Personality and Ability Testing, Inc.

Connelly, B. S. \& Ones, D. S. 2010. An other perspective on personality: Meta-analytic integration of observers' accuracy and predictive validity. Psychological Bulletin, 136(6): 1092-1122. 
Costa, P. T. \& McCrae, R. R. 1992a. Four Ways Five Factors are Basic. Personality and Individual Differences, 13(6): 653-665.

Costa, P. T. \& McCrae, R. R. 1992b. Revised NEO Personality Inventory (NEO-PI-R) and NEO Five-Factor Inventory (NEO-FFI) professional manual. Odessa, FL: Psychological Assessment Resources.

Costa, P. T. \& McCrae, R. R. 2008. The revised NEO personality inventory (NEO-PI-R). In G. J. Boyle, G. Matthews, \& D. H. Saklofske (Eds.), The SAGE Handbook of Personality Theory and Assessment. Thousand Oaks, CA: SAGE Publications.

D'Andrade, R. G. 1965. Trait psychology and componential analysis. American Anthropologist, 67(5): 215-228.

Darr, W. \& Kelloway, E. K. 2016. Sifting the Big Five: examining the criterion-related validity of facets. Journal of Organizational Effectiveness-People and Performance, 3(1): 2-22.

Deadrick, D. L. \& Gardner, D. G. 2008. Maximal and typical measures of job performance: An analysis of performance variability over time. Human Resource Management Review, 18(3): 133-145.

DeYoung, C. G., Quilty, L. C., \& Peterson, J. B. 2007. Between facets and domains: 10 aspects of the big five. Journal of Personality and Social Psychology, 93(5): 880-896.

Dudley, N. M., Orvis, K. A., Lebiecki, J. E., \& Cortina, J. M. 2006. A meta-analytic investigation of conscientiousness in the prediction of job performance: Examining the intercorrelations and the incremental validity of narrow traits. Journal of Applied Psychology, 91(1): 40-57.

Fiske, D. W. 1949. Consistency of the factorial structures of personality ratings from different sources. Journal of Abnormal and Social Psychology, 44(3): 329-344.

Fleeson, W. \& Law, M. K. 2015. Trait Enactments as Density Distributions: The Role of Actors, Situations, and Observers in Explaining Stability and Variability. Journal of Personality and Social Psychology, 109(6): 1090-1104.

Funder, D. C. \& West, S. G. 1993. Consensus, self-other agreement, and accuracy in personality judgment - An introduction. Journal of Personality, 61(4): 457-476.

Funder, D. C. 1995. On the accuracy of personality judgement: A realistic approach. Psychological Review, 102(4): 652-670.

Geukes, K., Nestler, S., Hutteman, R., Kuefner, A. C. P., \& Back, M. D. 2017. Trait personality and state variability: Predicting individual differences in within-and cross-context fluctuations in affect, self-evaluations, and behavior in everyday life. Journal of Research in Personality, 69: 124-138.

Goldberg, L. R. 1999. A broad-bandwidth, public-domain, personality inventory measuring the lower-level facets of several five-factor models. In I. Mervielde, I. Deary, F. De Fruyt, \& F. Ostendorf (Eds.), Personality Psychology in Europe, vol. 7: 7-28. Tilburg, Netherlands: Tilburg University Press.

Gough, H. G. \& Bradley, P. 2002. CPI Manual (3rd ed.). Mountain View, CA: CPP, Inc.

Graham, J. W. 2012. Planned missing data designs I: The 3-form design. In J. W. Graham (Ed.), Missing data: Analysis and design, statistics for social and behavioral sciences: 279294. New York, NY: Springer Science+Business Media.

Green, S. B. \& Babyak, M. A. 1997. Control of type I errors with multiple tests of constraints in structural equation modeling. Multivariate Behavioral Research, 32(1): 39-51. 
Green, S. B., Thompson, M. S., \& Poirer, J. 2001. An Adjusted Bonferroni Method for Elimination of Parameters in Specification Addition Searches. Structural Equation Modeling-a Multidisciplinary Journal, 8(1): 18-39.

Heller, D., Ferris, D., Brown, D., \& Watson, D. 2009. The influence of work personality on job satisfaction: Incremental validity and mediation effects. Journal of Personality, 77(4): 1051-1084.

Hogan, J. \& Hogan, R. 1989. How to measure employee reliability. Journal of Applied Psychology, 74(2): 273-279.

Hogan, J. \& Foster, J. 2013. Multifaceted personality predictors of workplace safety performance. Human Performance, 26(1): 20-43.

Hogan, R. 1996. A socioanalytic perspective on the Five-Factor model. In J. S. Wiggins (Ed.), The Five-Factor Model of Personality: Theoretical perspectives: 163-179. New York: The Guilford Press.

Hough, L. M. 1992. The big five personality variables - construct confusion: Description versus prediction. Human Performance, 5: 139-155.

Hough, L. M. \& Schneider, R. J. 1996. Personality traits, taxonomies, and applications in organizations. In K. R. Murphy (Ed.), Individual differences and behavior in organizations: 31-88: Jossey-Bass Publishers.

Hughes, D. J. \& Batey, M. 2017. Using personality questionnaires for selection. In H. Goldstein, E. Pulakos, J. Passmore, \& C. Semedo (Eds.), The Wiley Blackwell Handbook of the Psychology of Recruitment, Selection \& Retention. Chichester: Wiley-Blackwell.

Irwing, P. \& Booth, T. 2013. An item level exploratory factor analysis of the sphere of personality: An eleven-factor model. Paper presented at the First World Conference on Personality, Stellenbosch, South Africa.

Jackson, D. N. 1994. Jackson Personality Inventory-Revised manual. Port Huron, MI: Research Psychologists Press.

Jackson, D. N., Ashton, M. C., \& Tomes, J. L. 1996. The six-factor model of personality: Facets from the big five. Personality and Individual Differences, 21: 391-402.

Jackson, D. N., Paunonen, S. V., Fraboni, M., \& Goffin, R. G. 1996. A five-factor versus sixfactor model of personality structure. Personality and Individual Differences, 20: 33-45.

Jackson, D. N., Paunonen, S. V., \& Tremblay, P. F. 2000. Six Factor Personality Questionnaire Manual. Port Huron, MI: Sigma Assessment Systems.

Joreskog, K. G. 1971. Simultaneous factor analysis in several populations. Psychometrika, 36(4): 409-\&.

Joreskog, K. G. 1993. Testing structural equation models. In K. A. Bollen \& J. S. Long (Eds.), Testing structural equation models: 294-316. Newbury Park, CA: Sage.

Judge, T. A., Rodell, J. B., Klinger, R. L., Simon, L. S., \& Crawford, E. R. 2013. Hierarchical representations of the five-factor model of personality in predicting job performance: Integrating three organizing frameworks with two theoretical perspectives. Journal of Applied Psychology, 98(6): 875-925.

Kenny, D. A. 1979. Correlation and causation. New York, NY: Wiley.

Lee, K., Ashton, M. C., Hong, S. J., \& Park, K. B. 2000. Psychometric properties of the nonverbal personality questionnaire in Korea. Educational and Psychological Measurement, 60(1): 131-141.

Lee, K. \& Ashton, M. C. 2004. Psychometric properties of the HEXACO Personality Inventory. Multivariate Behavioral Research, 39: 329-358. 
McCrae, R. R. \& Costa, P. T. 1987. Validation of the 5-Factor Model of Personality across instruments and observers. Journal of Personality and Social Psychology, 52(1): 81-90.

McCrae, R. R. \& John, O. P. 1992. An introduction to the 5-Factor Model and its applications. Journal of Personality, 60(2): 175-215.

McCrae, R. R., Costa, P. T., Martin, T. A., Oryol, V. E., Rukavishnikov, A. A., Senin, I. G., Hrebickova, M., \& Urbanek, T. 2004. Consensual validation of personality traits across cultures. Journal of Research in Personality, 38(2): 179-201.

McDonald, R. P. 1999. Test theory: A unified treatment. Hillsdale: Erlbaum.

Millsap, R. E. \& Meredith, W. 2007. Factorial invariance: Historical perspectives and new problems. In R. Cudeck \& R. C. MacCallum (Eds.), Factor analysis at 100: Historical developments and future directions.: 131-152. Mahwah, NJ: Lawrence Erlbaum Associates, Publishers.

Minbashian, A., Wood, R. E., \& Beckmann, N. 2010. Task-Contingent Conscientiousness as a Unit of Personality at Work. Journal of Applied Psychology, 95(5): 793-806.

Motowidlo, S. J., Borman, W. C., \& Schmit, M. J. 1997. A theory of individual differences in task and contextual performance. Human Performance, 10(2): 71-83.

Mottus, R., McCrae, R. R., Allik, J., \& Realo, A. 2014. Cross-rater agreement on common and specific variance of personality scales and items. Journal of Research in Personality, 52: 47-54.

Murphy, K. R. \& Dzieweczynski, J. L. 2005. Why don't measures of broad dimensions of personality perform better as predictors of job performance? Human Performance, 18(4): 343-359.

Norman, W. T. 1963. Toward an adequate taxonomy of personality attributes - replicated factor structure in peer nomination personality ratings. Journal of Abnormal Psychology, 66(6): 574-\&.

O'Neill, T. A. \& Paunonen, S. V. 2013. Breadth in personality assessment: Implications for understanding and prediction of work behavior. In N. D. Christiansen \& R. P. Tett (Eds.), Handbook of Personality at Work: 299-332. New York, NY.

Oh, I. S., Wang, G., \& Mount, M. K. 2011. Validity of Observer Ratings of the Five-Factor Model of Personality Traits: A Meta-Analysis. Journal of Applied Psychology, 96(4): $762-773$.

Ones, D. S., Viswesvaran, C., \& Schmidt, F. L. 1993. Comprehensive meta-analysis of integrity test validities - Findings and implications for personnel-selection and theories of job performance. Journal of Applied Psychology, 78(4): 679-703.

Ones, D. S. \& Viswesvaran, C. 2001. Personality at work: Criterion-focused occupational personality scales used in personnel selection. In B. W. Roberts \& R. Hogan (Eds.), Personality Psychology in the Workplace: 63-92. Washington DC: American Psychological Association.

Parrigon, S., Woo, S. E., Tay, L., \& Wang, T. 2017. CAPTION-ing the Situation: A LexicallyDerived Taxonomy of Psychological Situation Characteristics. Journal of Personality and Social Psychology, 112(4): 642-681.

Passini, F. T. \& Norman, W. T. 1966. A universal conception of personality structure. Journal of Personality and Social Psychology, 4(1): 44-\&.

Paunonen, S. V. \& Jackson, D. N. 2000. What is beyond the Big Five? Plenty! Journal of Personality, 68(5): 821-835. 
Paunonen, S. V., Haddock, G., Forsterling, F., \& Keinonen, M. 2003. Broad versus narrow personality measures and the prediction of behaviour across cultures. European Journal of Personality, 17(6): 413-433.

Petrides, K. V. 2009. Psychometric Properties of the Trait Emotional Intelligence Questionnaire (TEIQue). Assessing Emotional Intelligence: Theory, Research, and Applications: 85101.

Pratto, F., Sidanius, J., Stallworth, L. M., \& Malle, B. F. 1994. Social-dominance orientation - A personality variable predicting social and political attitudes. Journal of Personality and Social Psychology, 67(4): 741-763.

Rauthmann, J. F., Gallardo-Pujol, D., Guillaume, E. M., Todd, E., Nave, C. S., Sherman, R. A., Ziegler, M., Jones, A. B., \& Funder, D. C. 2014. The Situational Eight DIAMONDS: A Taxonomy of Major Dimensions of Situation Characteristics. Journal of Personality and Social Psychology, 107(4): 677-718.

Rauthmann, J. F. \& Sherman, R. A. 2016. Ultra-Brief Measures for the Situational Eight DIAMONDS Domains. European Journal of Psychological Assessment, 32(2): 165174.

Rojon, C., McDowall, A., \& Saunders, M. N. K. 2015. The Relationships Between Traditional Selection Assessments and Workplace Performance Criteria Specificity: A Comparative Meta-Analysis. Human Performance, 28(1): 1-25.

Saucier, G. \& Goldberg, L. R. 1998. What is beyond the big five? Journal of Personality, 66(4): 495-524.

Schmidt, F. L. \& Hunter, J. E. 1998. The validity and utility of selection methods in personnel psychology: Practical and theoretical implications of 85 years of research findings. Psychological Bulletin, 124(2): 262-274.

Sherman, R. A., Rauthmann, J. F., Brown, N. A., Serfass, D. G., \& Jones, A. B. 2015. The Independent Effects of Personality and Situations on Real-Time Expressions of Behavior and Emotion. Journal of Personality and Social Psychology, 109(5): 872-888.

Tellegen, A. 1995. Multidimensional Personality Questionnaire - 276 (MPQ-276) test booklet. Minneapolis: University of Minnesota Press.

Tellegen, A. \& Waller, N. G. 2008. Exploring personality through test construction:

Development of the Multidimensional Personality Questionnaire. In G. J. M. Boyle, G. \& D. H. Saklofske (Eds.), The Sage handbook of personality theory and assessment, vol. 2. London: SAGE Publications.

Tett, R. P., Steele, J. R., \& Beauregard, R. S. 2003. Broad and narrow measures on both sides of the personality-job performance relationship. Journal of Organizational Behavior, 24(3): 335-356.

Tupes, E. C. \& Christal, R. E. 1961. Recurrent Personality Factors based on Trait Ratings (ASDTR-61-97). In P. L. Aeronautical Systems Division (Ed.). Lackland Air Force Base, TX.

Vazire, S. 2006. Informant reports: A cheap, fast, and easy method for personality assessment. Journal of Research in Personality, 40(5): 472-481.

Vazire, S. 2010. Who Knows What About a Person? The Self-Other Knowledge Asymmetry (SOKA) Model. Journal of Personality and Social Psychology, 98(2): 281-300.

Wiggins, J. S. 1992. Have model, will travel. Journal of Personality, 60(2): 527-532.

Woo, S. E., Chernyshenko, O. S., Stark, S. E., \& Conz, G. 2014. Validity of Six Openness Facets in Predicting Work Behaviors: A Meta-Analysis. Journal of Personality Assessment, 96(1): 76-86. 
ID13292

\section{TABLES}

Table 1. Descriptive Statistics and Correlations of Study Variables by Regression Model

\begin{tabular}{|c|c|c|c|c|c|}
\hline \multirow{2}{*}{\multicolumn{6}{|c|}{$\begin{array}{l}\text { Variable } \\
\text { Model } 1 \text { - Leading }\end{array}$}} \\
\hline & & & & & \\
\hline 1 Social Dependence & 1.04 & .71 & & & \\
\hline 2 Leadership & .86 & .10 & .14 & & \\
\hline 3 Integrity & 1.45 & -.11 & $.63 * * *$ & .82 & \\
\hline 4 Leading & 1.32 & $-.35 * * *$ & $.35 * *$ & $.32 * * *$ & .84 \\
\hline \multicolumn{6}{|l|}{ Model 2 - Supporting } \\
\hline 1 Empathy & .788 & .52 & & & \\
\hline 2 Complexity & 2.12 & -.14 & .58 & & \\
\hline 3 Supporting & 1.87 & $.40 * * *$ & $.25 * *$ & .86 & \\
\hline \multicolumn{6}{|l|}{ Model 3 - Interacting } \\
\hline 1 Leadership & 1.04 & .14 & & & \\
\hline 2 Empathy & .64 & $.30^{*}$ & .52 & & \\
\hline 3 Interacting & .94 & $.40 * * *$ & $.43 * * *$ & .88 & \\
\hline \multicolumn{6}{|l|}{ Model 4 - Analyzing } \\
\hline 1 Integrity & 1.94 & .82 & & & \\
\hline 2 Leadership & 1.29 & $.65 * * *$ & .14 & & \\
\hline 3 Analyzing & .74 & $.50 * * *$ & $.51 * * *$ & .85 & \\
\hline \multicolumn{6}{|l|}{ Model 5 - Creating } \\
\hline 1 Integrity & 1.77 & .82 & & & \\
\hline 2 Self-discipline & 1.65 & $.67 * * *$ & .72 & & \\
\hline 3 Leadership & 1.40 & $.64 * * *$ & $.59 * * *$ & .14 & \\
\hline 4 Creating & 1.79 & $.49 * * *$ & $.43 * * *$ & $0.43 * * *$ & .87 \\
\hline \multicolumn{6}{|l|}{ Model 6 - Organizing } \\
\hline 1 Harm avoidance & 2.21 & .76 & & & \\
\hline 2 Orderliness & 1.75 & $.20 *$ & .70 & & \\
\hline 3 Organizing & 2.58 & $.33^{* *}$ & $.35 * * *$ & .89 & \\
\hline \multicolumn{6}{|l|}{ Model 7 - Adapting } \\
\hline 1 Integrity & 1.90 & .82 & & & \\
\hline 2 Anxiety & .83 & $-.50 * * *$ & .85 & & \\
\hline 3 Adapting & 1.66 & $.41 * * *$ & $-.29 * * *$ & .81 & \\
\hline \multicolumn{6}{|l|}{ Model 8 - Enterprising } \\
\hline 1 Integrity & 2.06 & .82 & & & \\
\hline 2 Harm avoidance & 2.32 & -.16 & .76 & & \\
\hline 3 Enthusiasm & .833 & $.37 * * *$ & $-.20 *$ & .88 & \\
\hline 4 Enterprising & 1.62 & $.27 * *$ & $.22 *$ & $.18^{*}$ & .72 \\
\hline \multicolumn{6}{|l|}{ Model 9 - Overall } \\
\hline 1 Integrity & 1.28 & .82 & & & \\
\hline 2 Leadership & 1.34 & $.65 * * *$ & .14 & & \\
\hline 3 Overall & .50 & $.39 * * *$ & $.39 * * *$ & .84 & \\
\hline
\end{tabular}


ID13292

Table 2. Fit Statistics for Eleven CFA Models on Three Samples

\begin{tabular}{|c|c|c|c|c|c|}
\hline Model Sample & $\chi^{2}$ & $\mathrm{~d} f$ & CFI & TLI & RMSEA [90\% \\
\hline \multicolumn{6}{|l|}{ 1. Assertiveness } \\
\hline Sample 1 & $264.20 * * *$ & 111 & .94 & .93 & $.08[.07, .09]$ \\
\hline Sample 2 & $315.58 * * *$ & 111 & .93 & .91 & $.09[.08, .10]$ \\
\hline Sample 3 & $338.98 * * *$ & 111 & .90 & .88 & $.08[.07, .09]$ \\
\hline \multicolumn{6}{|c|}{ 2. Social Astuteness } \\
\hline Sample 1 & $45.20 *$ & 28 & .99 & .98 & $.05[.03, .08]$ \\
\hline Sample 2 & $93.25 * * *$ & 28 & .96 & .93 & $.10[.08, .12]$ \\
\hline Sample 3 & $47.45^{* *}$ & 28 & .98 & .97 & $.05[.02, .07]$ \\
\hline \multicolumn{6}{|l|}{ 3. Sociability } \\
\hline Sample 1 & $170.51 * * *$ & 92 & .95 & .93 & $.06[.05, .08]$ \\
\hline Sample 2 & $186.50 * * *$ & 92 & .96 & .94 & $.07[.05, .08]$ \\
\hline Sample 3 & $192.00 * * *$ & 92 & .96 & .94 & $.06[.05, .07]$ \\
\hline \multicolumn{6}{|l|}{ 4. Aggression } \\
\hline Sample 1 & $48.10 * * *$ & 16 & .98 & .96 & $.09[.05, .13]$ \\
\hline Sample 2 & $58.42 * * *$ & 16 & .97 & .95 & $.11[.08, .14]$ \\
\hline Sample 3 & $29.17 *$ & 16 & .99 & .98 & $.05[.02, .08]$ \\
\hline
\end{tabular}

5. Positive Affect

Sample 1

$136.84 * * *$

$84 \quad .99$

.98

$.05[.04, .07]$

Sample 2

$169.00 * * *$

$84 \quad .97$

.97

$.07[.05, .08]$

Sample 3

$279.12 * * *$

$84 \quad .94$

.93

$.08[.07, .09]$

6. Externalizing

Sample 1

$129.18^{* * *}$

$55 \quad .95$

.93

$.08[.06, .09]$

Sample 2

$94.94 * * *$

55

.98

.98

$.06[.04, .08]$

Sample 3

$138.76 * * *$

55

.95

.93

$.07[.05, .08]$ 
ID13292

\begin{tabular}{|c|c|c|c|c|c|c|}
\hline \multicolumn{2}{|c|}{ Model Sample } & $\chi^{2}$ & $\mathrm{~d} f$ & CFI & TLI & RMSEA [90\% CIs] \\
\hline \multicolumn{7}{|c|}{ 7. Conscientiousness } \\
\hline & ample 1 & $595.69 * * *$ & 349 & .95 & .95 & $.06[.05, .06]$ \\
\hline & Sample 2 & $667.58 * * *$ & 349 & .96 & .95 & $.06[.06, .07]$ \\
\hline & ample 3 & $637.38 * * *$ & 349 & .94 & .93 & $.05[.04, .06]$ \\
\hline \multicolumn{7}{|c|}{ 8. Prejudice } \\
\hline & ample 1 & $116.68 * * *$ & 51 & .90 & .87 & $.08[.06, .09]$ \\
\hline & ample 2 & $190.01 * * *$ & 51 & .85 & .82 & $.11[.09, .13]$ \\
\hline & ample 3 & $70.50 * *$ & 41 & .94 & .93 & $.05[.03, .07]$ \\
\hline \multicolumn{7}{|c|}{ 9. Resilience } \\
\hline & ample 1 & $146.87 * * *$ & 79 & .93 & .91 & $.06[.05, .08]$ \\
\hline & ample 2 & $157.01 * * *$ & 79 & .95 & .94 & $.07[.05, .08]$ \\
\hline & ample 3 & $173.44 * * *$ & 79 & .93 & .91 & $.06[.05, .07]$ \\
\hline \multicolumn{7}{|c|}{ 10. Openness } \\
\hline & ample 1 & $255.00 * * *$ & 142 & .95 & .94 & $.06[.05, .07]$ \\
\hline & ample 2 & $316.96 * * *$ & 142 & .95 & .94 & $.07[.06, .08]$ \\
\hline & ample 3 & $286.59 * * *$ & 142 & .94 & .93 & $.06[.05, .07]$ \\
\hline \multicolumn{7}{|c|}{ 11. Internalizing } \\
\hline & ample 1 & $247.09 * * *$ & 108 & .95 & .94 & $.08[.06, .09]$ \\
\hline & ample 2 & $327.94 * * *$ & 108 & .95 & .94 & $.09[.08, .11]$ \\
\hline & ample 3 & $384.83 * * *$ & 108 & .95 & .94 & $.09[.08, .10]$ \\
\hline
\end{tabular}

Note. $\chi^{2}=$ chi squared; $\mathrm{d} f=$ degrees of freedom; CFI = comparative fit index; TLI = Tucker-Lewis index; RMSEA = root mean square error of approximation; $\mathrm{CIs}=$ confidence intervals.

$* p<.05$

$* * p<.01$

$* * * p<.001$ 
Table 3. Correlations of Observer-rated Personality Facets and Manager-rated Job Performance

\begin{tabular}{|c|c|c|c|c|c|c|c|c|c|}
\hline & Leading & Supporting & Interacting & Analyzing & Creating & Organizing & Adapting & Enterprising & Overall \\
\hline \multicolumn{10}{|l|}{ Assertiveness } \\
\hline Assertiveness & $.35 * * *$ & .09 & .12 & .12 & .08 & -.08 & .07 & .06 & .12 \\
\hline Dominance & .07 & $.25 * * *$ & $.20 *$ & $.18 *$ & .09 & -.03 & $.23 * *$ & .13 & $.17 *$ \\
\hline Forgiveness & -.12 & $.17^{*}$ & $.18 *$ & -.05 & -.09 & -.03 & .12 & -.02 & .01 \\
\hline Stubbornness & -.04 & -.11 & -.16 & $-.27 * * *$ & -.12 & -.05 & $-.26 * *$ & -.02 & -.15 \\
\hline \multicolumn{10}{|l|}{ Social Astuteness } \\
\hline Narcissism & $.26^{* *}$ & -.06 & -.10 & -.11 & .03 & -.19 & .03 & .05 & -.04 \\
\hline Deviousness & .04 & -.04 & -.11 & $-.21 * *$ & -.12 & -.14 & -.01 & -.05 & -.10 \\
\hline Altruism & -.04 & .15 & $.31 * * *$ & .11 & .06 & .02 & .17 & .07 & .12 \\
\hline Empathy & .16 & $.35 * * *$ & $.36 * * *$ & $.31 * * *$ & $.26 * * *$ & $.22 *$ & $.28 * *$ & .15 & $.28 * * *$ \\
\hline \multicolumn{10}{|l|}{ Sociability } \\
\hline Sociability & -.04 & .13 & .05 & .11 & .02 & .15 & .08 & .10 & .09 \\
\hline Self-Reliance & .15 & $-.16^{*}$ & -.03 & .07 & .09 & .01 & -.04 & .02 & .03 \\
\hline Social Boldness & .09 & .07 & .06 & .01 & -.08 & -.12 & -.10 & .00 & .00 \\
\hline Leadership & $.34 * *$ & .18 & $.37 * * *$ & $.44 * * *$ & $.35 * * *$ & $.21 *$ & $.27 *$ & .11 & $.35 * * *$ \\
\hline Social Dependence & $-.35 * * *$ & -.02 & -.09 & -.12 & -.18 & .01 & $-.25 *$ & -.13 & -.16 \\
\hline \multicolumn{10}{|l|}{ Aggression } \\
\hline Excitement Seeking & -.07 & -.07 & -.11 & -.14 & -.12 & -.03 & .00 & -.08 & -.10 \\
\hline Harm Avoidance & .12 & $.25 *$ & .12 & $.27 * *$ & $.21 *$ & $.34 * * *$ & .02 & $.25 * *$ & $.24 *$ \\
\hline Alienation & -.05 & -.05 & $-.23 * * *$ & $-.17^{*}$ & -.10 & -.13 & $-.19 * *$ & -.10 & $-.17 *$ \\
\hline \multicolumn{10}{|l|}{ Positive Affect } \\
\hline Optimism & .07 & .17 & .16 & .12 & .03 & -.05 & .19 & .10 & .11 \\
\hline
\end{tabular}


ID13292

\begin{tabular}{|c|c|c|c|c|c|c|c|c|c|}
\hline & Leading & Supporting & Interacting & Analyzing & Creating & Organizing & Adapting & Enterprising & Overall \\
\hline Vigor & -.07 & -.16 & -.17 & -.11 & .01 & -.14 & -.08 & -.04 & -.11 \\
\hline Seriousness & $.17^{*}$ & -.07 & -.05 & .01 & .08 & .05 & -.03 & .06 & .03 \\
\hline Enthusiasm & .06 & $.29 * * *$ & $.30 * * *$ & .04 & .02 & .03 & .17 & $.18 *$ & .15 \\
\hline \multicolumn{10}{|l|}{ Externalizing } \\
\hline Negativity & -.05 & -.09 & $-.28 * * *$ & $-.19 * *$ & -.06 & $-.20 * *$ & $-.16^{*}$ & -.06 & $-.17 *$ \\
\hline Callousness & -.07 & -.18 & $-.23 *$ & $-.29 * *$ & -.15 & $-.23 *$ & -.19 & -.11 & $-.22 *$ \\
\hline Lack of Remorse & -.02 & -.07 & $-.16^{*}$ & $-.19 *$ & -.11 & -.12 & -.08 & -.08 & -.13 \\
\hline \multicolumn{10}{|l|}{ Conflicted } \\
\hline Relationships & .00 & -.17 & -.12 & $-.25 * *$ & $-.30 * * *$ & $-.25 * *$ & $-.27 * *$ & -.18 & $-.23 *$ \\
\hline Inferiority & -.16 & .04 & -.15 & -.16 & -.08 & -.09 & -.11 & .00 & -.11 \\
\hline \multicolumn{10}{|l|}{ Conscientiousness } \\
\hline Planfulness & .15 & .14 & $.19 *$ & $.30 * * *$ & $.22 * *$ & $.25 * * *$ & .12 & .16 & $.25 * *$ \\
\hline \multicolumn{10}{|l|}{ Practical vs } \\
\hline Imaginative & .11 & -.02 & .14 & .13 & .07 & .04 & .08 & .04 & .09 \\
\hline Impulsivity & .15 & $.18^{*}$ & $.18^{*}$ & $.30 * * *$ & $.18^{*}$ & $.20 * *$ & $.24 * * *$ & .10 & $.22 * * *$ \\
\hline Orderliness & .02 & .02 & .08 & .15 & .17 & $.32 * * *$ & .15 & .09 & .14 \\
\hline Detail Consciousness & .02 & .13 & .16 & $.17^{*}$ & .09 & $.22 * * *$ & -.02 & .08 & .12 \\
\hline Self-Discipline & $.31 * * *$ & .11 & .19 & $.37 * * *$ & $.37 * * *$ & $.22 *$ & $.23 *$ & $.18 *$ & $.31 * * *$ \\
\hline Competence & .17 & $.19 *$ & $.25^{* *}$ & $.28 * * *$ & $.23 * *$ & $.25 * * *$ & .04 & .11 & $.23 * *$ \\
\hline Integrity & $.32 * * *$ & $.23 * *$ & $.31 * * *$ & $.44 * * *$ & $.42 * * *$ & $.22 * *$ & $.41 * * *$ & $.26 * * *$ & $.39 * * *$ \\
\hline \multicolumn{10}{|l|}{ Prejudice } \\
\hline Traditionalism & .13 & -.06 & .08 & .13 & .10 & .07 & .05 & .04 & .08 \\
\hline Complexity & .14 & $.26 * * *$ & .12 & .00 & -.05 & .08 & .13 & .15 & .12 \\
\hline
\end{tabular}


ID13292

\begin{tabular}{|c|c|c|c|c|c|c|c|c|c|}
\hline & Leading & Supporting & Interacting & Analyzing & Creating & Organizing & Adapting & Enterprising & Overall \\
\hline Openness to Change & -.12 & $.20 * *$ & .06 & $.16^{*}$ & .01 & .01 & .01 & -.05 & .04 \\
\hline \multicolumn{10}{|l|}{ Resilience } \\
\hline Fearfulness & -.07 & .08 & -.06 & .02 & .09 & .17 & -.07 & $.16^{*}$ & .04 \\
\hline Achievement & .21 & .08 & .05 & $.21 *$ & $.33 * * *$ & .10 & $.27 * *$ & .12 & .19 \\
\hline Sensitivity & -.04 & .07 & .06 & .07 & .10 & .04 & .02 & .03 & .06 \\
\hline Risk-taking & .02 & -.11 & -.11 & -.04 & -.02 & -.05 & -.03 & -.09 & -.06 \\
\hline Tolerance & -.06 & .21 & .12 & .07 & -.03 & .01 & .09 & -.02 & .05 \\
\hline \multicolumn{10}{|l|}{ Openness } \\
\hline Intellectual Curiosity & .07 & .08 & .01 & $.20 * * *$ & $.17^{*}$ & .11 & .12 & .02 & .11 \\
\hline Aesthetic Interests & .05 & $.27 * * *$ & $.17 * *$ & $.15^{*}$ & .10 & .15 & .06 & .12 & $.16^{*}$ \\
\hline Creativity & .10 & .05 & .07 & $.24 * *$ & $.23 * *$ & .19 & $.23^{*}$ & $.17 *$ & .19 \\
\hline Fantasy & -.12 & -.02 & $-.14 *$ & $-.16^{*}$ & -.13 & -.11 & -.07 & -.02 & -.12 \\
\hline Perseverance & -.08 & -.10 & -.11 & .14 & .14 & -.04 & .07 & -.02 & .01 \\
\hline \multicolumn{10}{|l|}{ Internalizing } \\
\hline Anxiety & $-.21 *$ & -.03 & $-.18 *$ & $-.26 * * *$ & -.13 & -.02 & $-.29 * * *$ & -.04 & $-.17 *$ \\
\hline Worry & $-.18^{*}$ & .03 & -.12 & -.12 & -.04 & .04 & -.16 & .02 & -.08 \\
\hline Depression & -.06 & -.05 & -.16 & -.17 & -.06 & -.05 & -.15 & -.08 & -.13 \\
\hline Rumination & -.07 & .03 & -.10 & -.03 & .03 & -.08 & -.05 & -.08 & -.05 \\
\hline Self Consciousness & -.02 & -.01 & -.04 & -.01 & .08 & .04 & .08 & .11 & .04 \\
\hline
\end{tabular}

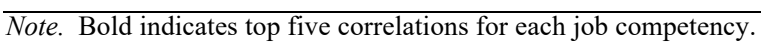

$* p<.05$

$* * p<.01$

$* * * p<.001$ 
Table 4. Parameter Estimates and Variance Explained for Nine Regression Models

\begin{tabular}{|c|c|c|c|c|c|}
\hline \multirow{3}{*}{$\begin{array}{cc} & \text { Job } \\
& \text { competency } \\
1 & \text { Jeading }\end{array}$} & \multirow{2}{*}{$\begin{array}{l}\text { Personality } \\
\text { facets }\end{array}$} & \multicolumn{2}{|c|}{ Sample 1} & \multicolumn{2}{|c|}{ Sample 2} \\
\hline & & $\beta$ & $r^{2}$ & $\beta$ & $r^{2}$ \\
\hline & & & $.24 * *$ & & $.21 *$ \\
\hline & Social dependence & $-.32 * * *$ & & -.15 & \\
\hline & Leadership & .23 & & $.42 * *$ & \\
\hline & Integrity & .14 & & .02 & \\
\hline \multirow[t]{3}{*}{ 2. Supporting } & & & $.25 * *$ & & $.30 * *$ \\
\hline & Empathy & $.44 * * *$ & & $.56^{* * *}$ & \\
\hline & Complexity & $.31 * *$ & & .09 & \\
\hline \multirow[t]{3}{*}{ 3. Interacting } & & & $.27^{*}$ & & $.14^{*}$ \\
\hline & Leadership & $.30 *$ & & $.31 *$ & \\
\hline & Empathy & $.34 * *$ & & .09 & \\
\hline \multirow[t]{3}{*}{ 4. Analyzing } & & & $.31 * * *$ & & .08 \\
\hline & Integrity & $.30^{*}$ & & .05 & \\
\hline & Leadership & .31 & & .24 & \\
\hline \multirow[t]{4}{*}{ 5. Creating } & & & $.27 * * *$ & & .08 \\
\hline & Integrity & .31 & & .12 & \\
\hline & Self-discipline & .13 & & -.31 & \\
\hline & Leadership & .15 & & .31 & \\
\hline \multirow[t]{3}{*}{ 6. Organizing } & & & $.20 * *$ & & .06 \\
\hline & Harm avoidance & $.28 * *$ & & .01 & \\
\hline & Orderliness & $.29 * * *$ & & $.24 * *$ & \\
\hline \multirow[t]{3}{*}{ 7. Adapting } & & & $.18^{*}$ & & $.14 * *$ \\
\hline & Integrity & $.35 * *$ & & .17 & \\
\hline & Anxiety & -.12 & & $-.26 * *$ & \\
\hline \multirow[t]{4}{*}{ 8. Enterprising } & & & $.15^{*}$ & & $.13 *$ \\
\hline & Integrity & $.26^{* *}$ & & $.21 *$ & \\
\hline & Harm avoidance & $.28 * *$ & & .14 & \\
\hline & Enthusiasm & .14 & & .21 & \\
\hline \multirow[t]{3}{*}{ 9. Overall } & & & $.18^{*}$ & & .10 \\
\hline & Integrity & .23 & & .15 & \\
\hline & Leadership & .24 & & .20 & \\
\hline \multicolumn{6}{|c|}{ Note. $\beta=$ Beta weight for each personality trait. $r 2=$ variance explained of the complete model. } \\
\hline \multicolumn{6}{|c|}{${ }^{*} p<.05$} \\
\hline \multicolumn{6}{|l|}{$* * p<.01$} \\
\hline$* * * p<.001$ & & & & & \\
\hline
\end{tabular}


Table 5. Fit Statistics for Nine Regression Models

\begin{tabular}{|c|c|c|c|c|c|c|}
\hline Model & Sample & $\chi^{2}$ & $\mathrm{~d} f$ & CFI & TLI & RMSEA $[90 \% \mathrm{CIs}]$ \\
\hline \multicolumn{7}{|c|}{ 1. Leading } \\
\hline & Sample 1 & $119.90 * *$ & 83 & .99 & .98 & $.04[.02, .06]$ \\
\hline & Sample 2 & $131.80 * * *$ & 83 & .98 & .98 & $.05[.03, .06]$ \\
\hline
\end{tabular}

2. Supporting

$\begin{array}{llllll}\text { Sample 1 } & 169.53^{* * *} & 24 & .96 & .95 & .14[.12, .16] \\ \text { Sample 2 } & 184.95^{* * *} & 24 & .96 & .94 & .15[.13, .17]\end{array}$

3. Interacting

$\begin{array}{rrrrrr}\text { Sample 1 } & 78.36^{* * *} & 40 & .99 & .98 & .06[.04, .08] \\ \text { Sample 2 } & 180.35^{* * *} & 40 & .98 & .98 & .05[.03, .06]\end{array}$

4. Analyzing

$\begin{array}{llllll}\text { Sample 1 } & 124.17^{* *} & 85 & .99 & .99 & .04[.02, .06] \\ \text { Sample 2 } & 119.99^{* *} & 85 & .99 & .99 & .04[.02, .05]\end{array}$

5. Creating

$\begin{array}{llllll}\text { Sample 1 } & 203.25 * * * & 127 & .99 & .99 & .05[.03, .06] \\ \text { Sample 2 } & 195.69 * * * & 127 & .99 & .99 & .04[.03, .06]\end{array}$

6. Organizing

$\begin{array}{llllll}\text { Sample 1 } & 117.06^{* * * *} & 50 & .99 & .98 & .07[.05, .09] \\ \text { Sample 2 } & 128.73^{* * *} & 50 & .99 & .99 & .04[.03, .06]\end{array}$

7. Adapting

$\begin{array}{llllll}\text { Sample 1 } & 207.96^{* * *} & 101 & .96 & .96 & .06[.05, .07] \\ \text { Sample 2 } & 184.87^{* * *} & 101 & .98 & .97 & .05[.04, .07]\end{array}$

8. Enterprising

$\begin{array}{llllll}\text { Sample 1 } & 493.52 & 146 & .94 & .93 & .09[.08, .10] \\ \text { Sample 2 } & 569.13^{* * * *} & 146 & .92 & .90 & .10[.09, .11]\end{array}$

9. Overall

$\begin{array}{llllll}\text { Sample 1 } & 52.06^{* *} & 33 & .99 & .99 & .05[.02, .07] \\ \text { Sample 2 } & 68.31^{* * *} & 33 & .99 & .98 & .06[.04, .08]\end{array}$

Note. $\chi^{2}=$ chi squared; $\mathrm{df}=$ degrees of freedom; $\mathrm{CFI}=$ comparative fit index; TLI = Tucker-Lewis index; RMSEA = root mean square error of approximation; CIs $=$ confidence intervals.

$*_{p}<.05$

$* * p<.01$

$* * * p<.001$ 